\title{
SPECTRAL AND LUMINESCENT PROPERTIES AND MORPHOLOGY OF SELF-ASSEMBLED NANOSTRUCTURES OF AN INDOTRICARBOCYANINE DYE
}

\author{
N. V. Belko, ${ }^{*}$ M. P. Samtsov, G. A. Gusakov, \\ D. S. Tarasau, A. A. Lugovski, and E. S. Voropay \\ UDC $535.37 ; 620.3 ; 547.97$
}

Spectral and luminescent properties of an indotricarbocyanine dye are studied in solutions and after deposition on quartz or silicon substrates. It is found that the dye molecules self-assemble in aqueous EtOH solutions to form $H^{*}$-aggregates. The absorption band of the $H^{*}$-aggregates shows a hypsochromic shift of $192 \mathrm{~nm}\left(5291 \mathrm{~cm}^{-1}\right)$ relative

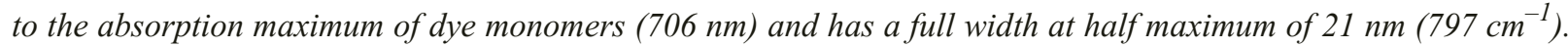
The morphology of the $H^{*}$-aggregates of the indotricarbocyanine dye is studied for the first time. It is found that the aggregates are rod-like species $\sim 10 \mathrm{~nm}$ high, $100 \mathrm{~nm}$ wide, and several micrometers long. H-aggregates with a fluorescence maximum at $560 \mathrm{~nm}$ and Stokes shift of $325 \mathrm{~cm}^{-1}$ in addition to non-fluorescent $H^{*}$-aggregates form in aqueous EtOH solutions and are nanoparticles with a height of 1-3 $\mathrm{nm}$ and lateral dimensions of $\sim 100 \mathrm{~nm}$.

Keywords: polymethine dyes, molecular aggregates, $H^{*}$-aggregates, spectral and luminescent properties, selfassembled nanostructures, morphology, atomic force microscopy.

Introduction. Polymethine (cyanine) dyes (PDs) are a class of organic compounds with unique properties. The optical properties of PDs are mainly due to polymethine chains in them consisting of an uneven number of conjugated methines. PDs are widely used as spectral sensitizers [1, 2], nonlinear media components [3-5], and fluorescent biological labels [6-8]. Photosensitizers based on them are being developed for photodynamic therapy [9-11] and other applications [12-14].

Many PDs form molecular aggregates in solutions [15]. PD aggregates are of interest for basic research because of their special optical [16-37] and electronic properties [38-43]. They find practical applications in nanophotonics [4449], nanoplasmonics [50-52], optoelectronics [53], solar energy [54-57], and other areas [58-63]. Therefore, the spectral, electrochemical, and optoelectronic properties of PD aggregates have been enthusiastically studied since their discovery in 1936 [64-66].

Two types of molecular aggregates, $\mathrm{J}$ and $\mathrm{H}$, are distinguished [1, 67]. J-aggregates characteristically have narrow absorption bands (ABs) that are shifted bathochromically relative to absorption maxima of the monomers [64, 65] and have strong fluorescence with a small Stokes shift [64]. Conversely, H-aggregates have ABs shifted to shorter wavelengths relative to the monomer ABs $[1,67]$ and widths in most instances that are comparable with those of the monomer ABs [1, 28, 56, 68, 69]. $\mathrm{H}$-aggregates do not typically fluoresce [1, 67] although exceptions are known [70-72]. Special H-aggregates with ABs of significantly smaller full width at half maximum (FWHM) than that of the monomer are formed in rare instances [1, 68, 72, 73] and are called $\mathrm{H}^{*}$-aggregates.

ABs with positions and shapes attributable to $\mathrm{H}^{*}$-aggregates were observed from an aqueous EtOH solution of one of the indotricarbocyanine dyes created at A. N. Sevchenko Research Institute of Applied Physical Problems, Belarusian State University [74]. Information on the spectral and luminescent properties and morphology of $\mathrm{H}^{*}$-aggregates is currently limited $[1,68,72,73]$. The present work reports spectral and luminescent properties and the morphology of $\mathrm{H}^{*}$-aggregates of an indotricarbocyanine dye in solution and on substrates because such aggregates are interesting from a fundamental viewpoint and for practical applications.

Experimental. The indotricarbocyanine dye was a symmetric cationic PD of molecular mass $742 \mathrm{~g} / \mathrm{mol}$ that was soluble in $\mathrm{EtOH}$ and other organic solvents but insoluble in $\mathrm{H}_{2} \mathrm{O}$ :

${ }^{*}$ To whom correspondence should be addressed.

A. N. Sevchenko Institute of Applied Physical Problems, Belarusian State University, 7 Kurchatov Str., Minsk, 220045, Belarus; email: nikita.belko@gmail.com. Translated from Zhurnal Prikladnoi Spektroskopii, Vol. 85, No. 6, pp. 868-878, November-December, 2018. Original article submitted August 6, 2018. 


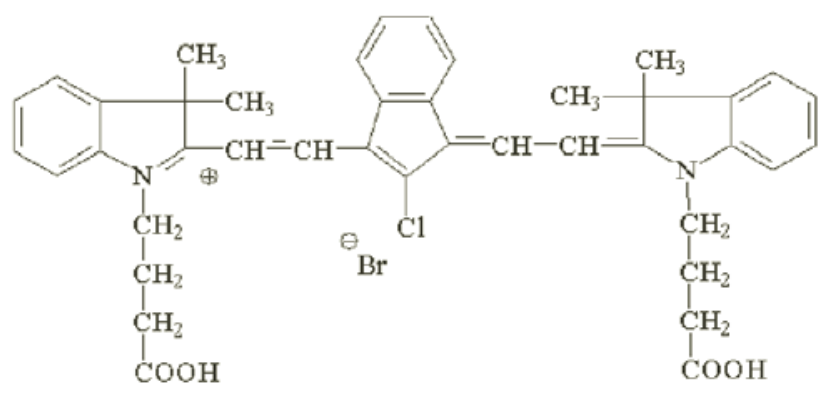

Samples were prepared by treating vigorously stirred concentrated solutions of dye in EtOH with deionized $\mathrm{H}_{2} \mathrm{O}$. Solutions with high dye concentrations $(>5 \mu \mathrm{M})$ were sonicated at $35 \mathrm{kHz}$ for $5-10$ min before taking measurements.

Absorption spectra were recorded using a SOLAR PV1251 or EssentOptics Photon RT spectrophotometer; fluorescence and excitation fluorescence spectra of solutions, a SPEX Fluorolog fluorescence spectrometer. Fluorescence spectra excited by laser radiation with $\lambda=514.5 \mathrm{~nm}$ (Ar laser) were measured on a SPEX Ramalog spectrometer using $50-0.13-\mathrm{mm}$ quartz cuvettes. Dye solutions were placed onto quartz substrates using a micropipettor and evaporated under ambient conditions for absorption and luminescence spectroscopy on solid substrates. The morphology of molecular dye aggregates on silica substrates was studied using an HT-MDT Solver P47-PRO atomic-force microscope.

Results and Discussion. A long-wavelength band with a shoulder on the short-wavelength edge that was characteristic for this class of compounds was observed in absorption spectrum of the dye in aqueous EtOH (5 vol.\% EtOH) at concentrations $<2 \mu \mathrm{M}$ (Fig. 1, curve 1) [15]. The shape of the dye absorption spectrum did not change upon dilution to $0.1 \mu \mathrm{M}$. The AB maximum was situated at $706 \mathrm{~nm}$ and had a FWHM of $94 \mathrm{~nm}\left(1978 \mathrm{~cm}^{-1}\right)$. The shape of the dye fluorescence spectrum in such solutions was independent of exciting wavelength. The band maximum was located at $738 \mathrm{~nm}$. The fluorescence quantum yield was $3 \%$. The position of the maximum in the dye fluorescence excitation spectrum coincided with the absorption maximum of $706 \mathrm{~nm}$. The results indicated that the solution contained one type of fluorescing center that could be attributed to dye monomers.

Increasing the dye concentration in aqueous EtOH $(>2 \mu \mathrm{M})$ (maintain EtOH at 5 vol.\%) changed the shape of its absorption spectrum (Fig. 1, curve 2). The long-wavelength region had a maximum at $706 \mathrm{~nm}$ and a distinct shoulder at $658 \mathrm{~nm}$, the relative contribution of which increased with increasing dye concentration. The FWHM of this AB increased to $175 \mathrm{~nm}\left(3936 \mathrm{~cm}^{-1}\right)$. Furthermore, a new narrow AB with a maximum at $517 \mathrm{~nm}$ and FWHM of $30 \mathrm{~nm}\left(1123 \mathrm{~cm}^{-1}\right)$ appeared in the short-wavelength region.

A maximum at $738 \mathrm{~nm}$ was observed in the dye fluorescence spectrum at any concentration (Fig. 1, curve 3) with excitation within the long-wavelength $\mathrm{AB}$. Fluorescence excitation spectra of the dye in the range 790-850 nm showed a single maximum (Fig. 1, curve 4) that practically coincided with the $\mathrm{AB}$ maximum at $706 \mathrm{~nm}$ that was observed at low dye concentrations. This correspondence between the fluorescence excitation spectrum and the absorption spectrum of a dilute solution indicated that only centers with an $\mathrm{AB}$ maximum at $706 \mathrm{~nm}$, i.e., dye monomers, fluoresced.

The absorption spectrum of dye at concentrations $>2 \mu \mathrm{M}$ changed over time after preparation. The optical density of the short-wavelength $\mathrm{AB}$ at $517 \mathrm{~nm}$ increased whereas that of the long-wavelength $\mathrm{AB}$ decreased (Fig. 2a). The FWHM of the short-wavelength $A B$ decreased to $21 \mathrm{~nm}\left(797 \mathrm{~cm}^{-1}\right)$ as the maximum shifted from 517 to $514 \mathrm{~nm}$. The optical density of the shoulder at $658 \mathrm{~nm}$ decayed faster over time than that of the AB at $706 \mathrm{~nm}$ (Fig. 2b). The FWHM of the long-wavelength AB decreased from $175 \mathrm{~nm}\left(3936 \mathrm{~cm}^{-1}\right)$ to $128 \mathrm{~nm}\left(2696 \mathrm{~cm}^{-1}\right)$. Absorption spectra gradually stopped changing and stabilized 60-120 min after adding $\mathrm{H}_{2} \mathrm{O}$ to the dye solution in EtOH (Fig. 2b). An isosbestic point at $545 \mathrm{~nm}$ appeared in the absorption spectra and indicated that the solution contained two types of centers absorbing at this spectral point with molar absorption coefficients that were equal at this wavelength. It is noteworthy that the shapes of stabilized dye solution absorption spectra did not change over several months.

Temperature effects on the spectral and luminescent properties of the dye were studied to establish the nature of the observed ABs (Fig. 3). These measurements were made using samples for which the absorption spectra had stopped changing over time, i.e., at least 120 min after preparation.

The $\mathrm{AB}$ at $514 \mathrm{~nm}$ weakened if the temperature was increased. It dropped relative to the contribution of the shortwavelength shoulder at $650 \mathrm{~nm}$ on the long-wavelength $\mathrm{AB}$ with a simultaneous increase of optical density at $706 \mathrm{~nm}$ (Fig. 3). The $\mathrm{AB}$ at $514 \mathrm{~nm}$ was practically unobserved at $60^{\circ} \mathrm{C}$. The optical density of the $\mathrm{AB}$ maximum at $706 \mathrm{~nm}$ increased by almost five times as compared with the value at $10^{\circ} \mathrm{C}$. The shape of the long-wavelength $\mathrm{AB}$ became close to that 


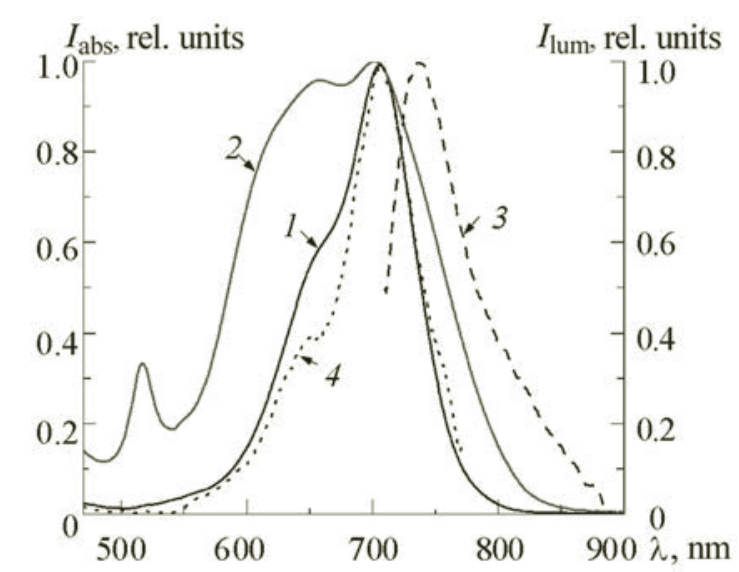

Fig. 1. Normalized absorption spectra at dye concentrations 0.5 (1) and $3.75 \mu \mathrm{M}(2)$; normalized fluorescence spectra for $\lambda_{\mathrm{ex}}=700 \mathrm{~nm}$ (3) and fluorescence excitation spectra for $\lambda_{\text {rec }}=790 \mathrm{~nm}$ (4) at dye concentration $3.75 \mu \mathrm{M}$; EtOH concentration 5 vol.\%.
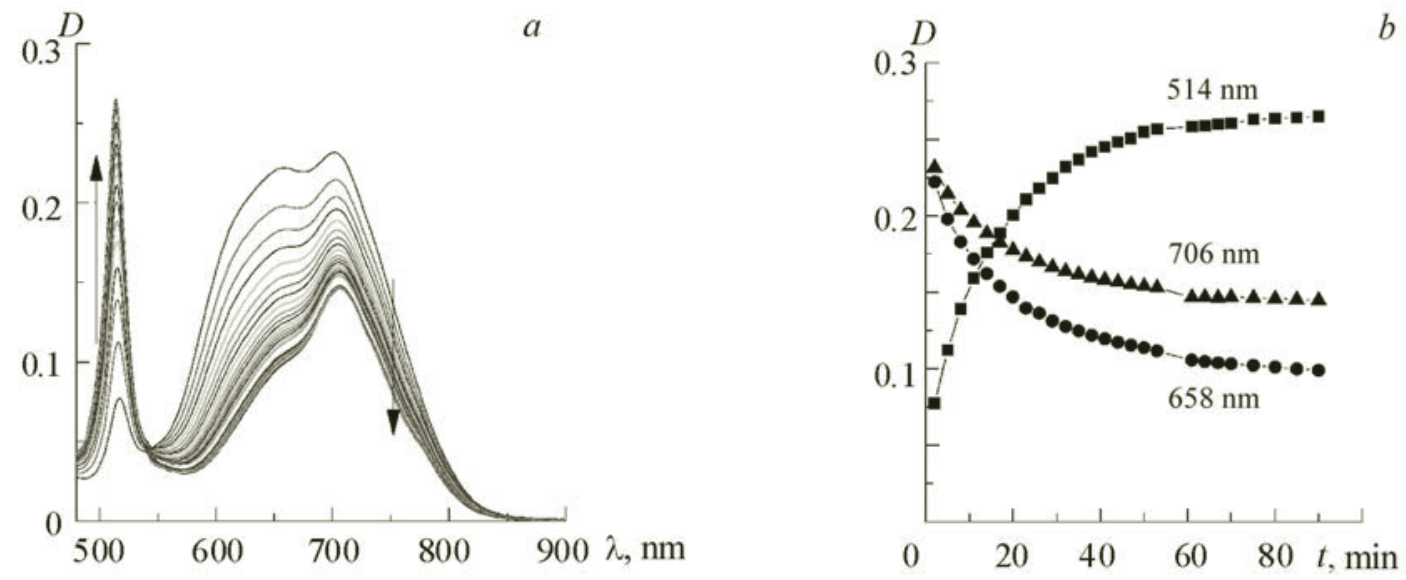

Fig. 2. Absorption spectra at dye concentration $3.75 \mu \mathrm{M}$ in aqueous EtOH (5 vol.\% EtOH) for 90 min after preparation of the solution (a); kinetics of optical density change at the indicated maxima (b).

in the spectrum of the dilute solution (Fig. 1, curve 1). The FWHM decreased to $81 \mathrm{~nm}\left(1637 \mathrm{~cm}^{-1}\right)$. The spectral changes were reversible. Subsequent cooling to the initial temperature restored the initial absorption spectrum so that the shortwavelength $\mathrm{AB}$ at $514 \mathrm{~nm}$ appeared again. The dye fluorescence spectrum with $\lambda_{\mathrm{ex}}=700 \mathrm{~nm}$ exhibited a broad band with a maximum at $738 \mathrm{~nm}$ at temperatures up to $50^{\circ} \mathrm{C}$. The fluorescence maximum shifted bathochromically upon further heating to $60^{\circ} \mathrm{C}$ to $747 \mathrm{~nm}$. The fluorescence intensity at $\lambda_{\mathrm{ex}}=700 \mathrm{~nm}$ increased with increasing temperature, reached a maximum at $50^{\circ} \mathrm{C}$, and then decreased at higher temperatures. The change of absorption spectrum shape upon heating and the increased fluorescence intensity indicated that the concentration of dye monomers increased. This was characteristic of organic dyes because the molecular aggregates decomposed into monomers as a result of increased intermolecular vibrational energy [1, $28,75]$.

The variable temperature and concentration measurements indicated that the fluorescence band maximum at $738 \mathrm{~nm}$ and its corresponding fluorescence excitation band maximum at $706 \mathrm{~nm}$ were due to dye monomers. The shoulder on the long-wavelength $\mathrm{AB}$ at $658 \mathrm{~nm}$ corresponded to non-fluorescent H-dimers because of the small hypsochromic shift of $1033 \mathrm{~cm}^{-1}$ relative to the monomer spectrum [1].

The decreased intensity and bathochromic shift of the fluorescence maximum upon heating to $>50^{\circ} \mathrm{C}$ were due to increased optical density in the overlap region of the $\mathrm{AB}$ and dye fluorescence band. An internal filter effect surely appeared because fluorescence spectra were recorded in a 1-cm cuvette in $90^{\circ}$ geometry although the optical density in the overlap region of the $\mathrm{AB}$ and fluorescence at this temperature was $~ 0.4$ [76]. Furthermore, the decreased fluorescence intensity at $>50^{\circ} \mathrm{C}$ was due to the reduced solution viscosity that led to fluorescence quenching [77]. 

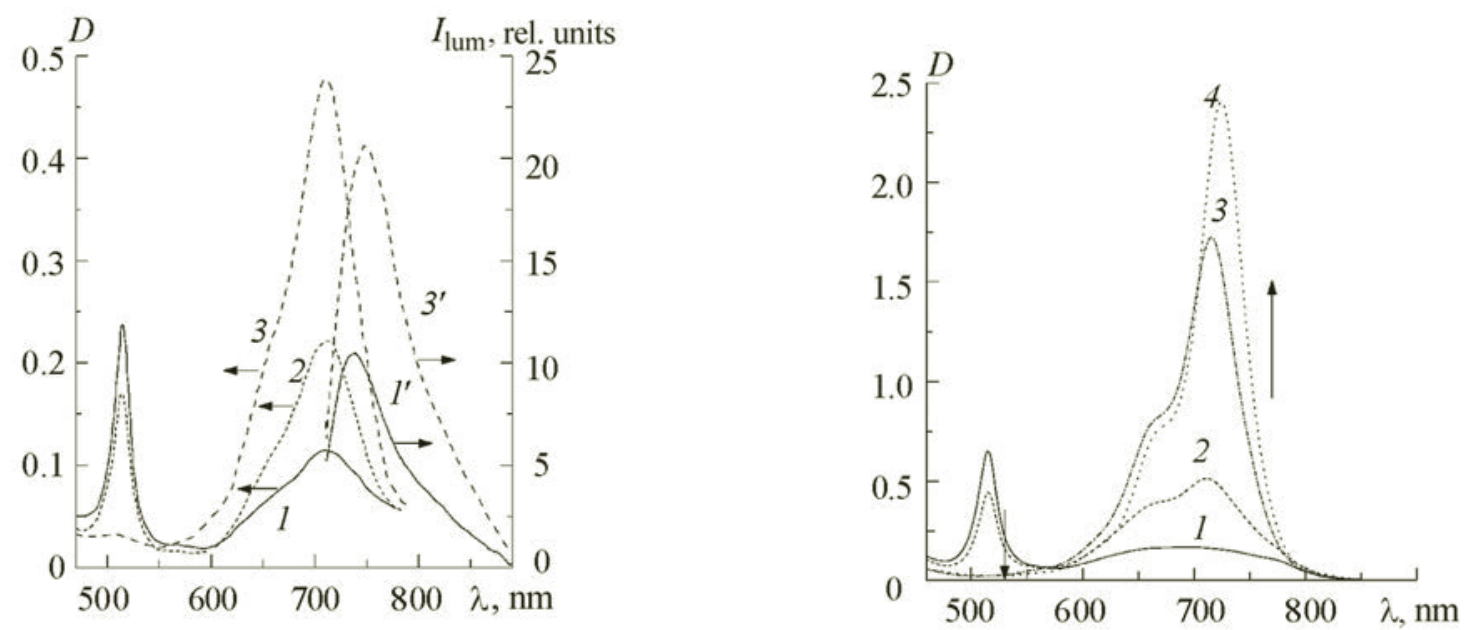

Fig. 3. Absorption (1) and fluorescence spectra $\left(1^{\prime}\right)$ at $10^{\circ} \mathrm{C}$; absorption spectrum at $40^{\circ} \mathrm{C}(2)$; absorption (3) and fluorescence spectra ( $3^{\prime}$ ) at $60^{\circ} \mathrm{C}$; dye, $3.75 \mu \mathrm{M} ; 5 \mathrm{vol} . \% \mathrm{EtOH}$; $\lambda_{\mathrm{ex}}=700 \mathrm{~nm}$.

Fig. 4. Change of dye absorption spectrum in aqueous EtOH with increasing EtOH concentration: 5 (1), 20 (2), 30 (3), and 100 vol.\% (4); dye concentration, $5 \mu \mathrm{M}$.

The small FWHM of the short-wavelength $\mathrm{AB}$ at $514 \mathrm{~nm}$ (only $21 \mathrm{~nm}$ or $797 \mathrm{~cm}^{-1}$ ) allowed it to be attributed to $\mathrm{H}^{*}$-aggregates [1]. The spectral shift of $5291 \mathrm{~cm}^{-1}$ for the $\mathrm{AB}$ of $\mathrm{H}^{*}$-aggregates relative to the maximum of the monomers was significantly greater than for most known molecular aggregates.

The effect of EtOH concentration on the shape of the dye absorption spectrum was studied (Fig. 4). It was found that the optical density of the $\mathrm{AB}$ at $514 \mathrm{~nm}$ decreased smoothly as the $\mathrm{EtOH}$ concentration increased whereas that of the $\mathrm{AB}$ at $706 \mathrm{~nm}$ increased simultaneously. The $\mathrm{AB}$ at $514 \mathrm{~nm}$ disappeared at EtOH concentration $\sim 30 \mathrm{vol} . \%$. The spectral changes were consistent with dissolution of dye aggregate molecules in EtOH.

The spectral properties of indotricarbocyanine dye aggregates deposited from aqueous EtOH onto quartz substrates were investigated. Solutions with a high dye concentration $(25 \mu \mathrm{M})$ were placed onto substrates to prepare solid samples. The absorption spectrum of dye on quartz substrate contained a short-wavelength band maximum at $522 \mathrm{~nm}$ and a broad long-wavelength band with maxima at 684 and $746 \mathrm{~nm}$ (Fig. 5). The AB intensity ratios differed for solutions and samples on substrates. The $\mathrm{AB}$ at $522 \mathrm{~nm}$ had a distinct long-wavelength shoulder at $\sim 550 \mathrm{~nm}$ that was not observed in the spectrum of dye in aqueous EtOH solution. On one hand, close and stronger bands could mask absorption at $550 \mathrm{~nm}$. Deposition of dye on substrate changed the optical density ratio in the different $\mathrm{ABs}$, as a result of which the shoulder at $550 \mathrm{~nm}$ became noticeable. On the other, centers absorbing at $550 \mathrm{~nm}$ could arise directly on the substrate during solvent evaporation.

Fluorescence excitation and emission spectra were studied to determine the reasons for the different shapes of the absorption spectra in solution and on a substrate. Excitation by laser radiation with $\lambda=514.5 \mathrm{~nm}$, i.e., at the $\mathrm{AB}$ maximum of $\mathrm{H}^{*}$-aggregates, in aqueous EtOH produced a fluorescence spectrum with maxima at 560, 624, and $738 \mathrm{~nm}$ (Fig. 6, curve 1). Analogous fluorescence bands at 574 and $755 \mathrm{~nm}$ also appeared for dye deposited on quartz substrate from aqueous EtOH (curve 2). The long-wavelength band with maxima at $738 \mathrm{~nm}$ in solution and $757 \mathrm{~nm}$ on substrate was attributed to fluorescence of dye monomers [according to the fluorescence excitation spectrum and temperature changes (Figs. 1 and 3)]. The maximum at $624 \mathrm{~nm}$ in aqueous EtOH was shifted by $3400 \mathrm{~cm}^{-1}$ relative to the exciting laser line. The relative contribution of this band to the total spectrum increased if the solution was diluted. A band shifted by $3400 \mathrm{~cm}^{-1}$ relative to the excitation frequency appeared on going to $\lambda_{\mathrm{ex}}=496 \mathrm{~nm}$. Therefore, this maximum was due to Raman scattering of $\mathrm{H}_{2} \mathrm{O}$ molecules, the vibrations of which are active in the range $2900-3800 \mathrm{~cm}^{-1}$ [78].

The dye fluorescence excitation spectrum in aqueous EtOH was recorded at $\lambda=590 \mathrm{~nm}$ (Fig. 7, curve 2). It contained a single band maximum at $550 \mathrm{~nm}$. Therefore, centers responsible for the $\mathrm{AB}$ at $514 \mathrm{~nm}$ in solution (curve 3 ) were nonfluorescent. Furthermore, the position of the excitation spectrum maximum corresponded to the shoulder of the shortwavelength $\mathrm{AB}$ in the spectrum of dye on substrate (curve 4). It could be concluded based on these results that the fluorescence band maximum at $560 \mathrm{~nm}$ corresponded to absorption centers appearing at $\sim 550 \mathrm{~nm}$. Thus, the main maximum at $514 \mathrm{~nm}$ and 


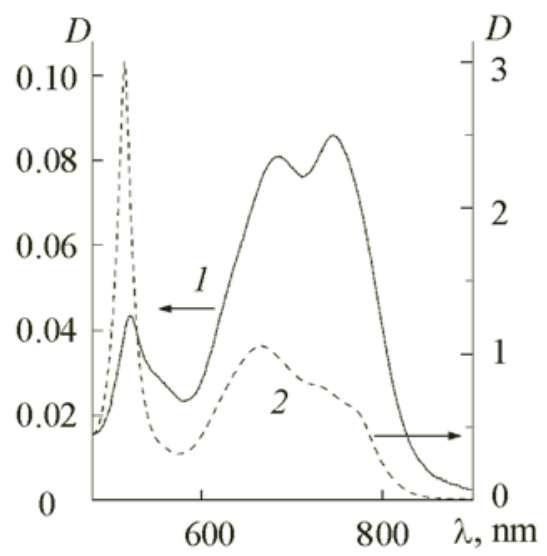

Fig. 5. Absorption spectra of dye $(25 \mu \mathrm{M})$ deposited on quartz substrate from aqueous EtOH (5 vol.\%) (1) and before deposition (2).
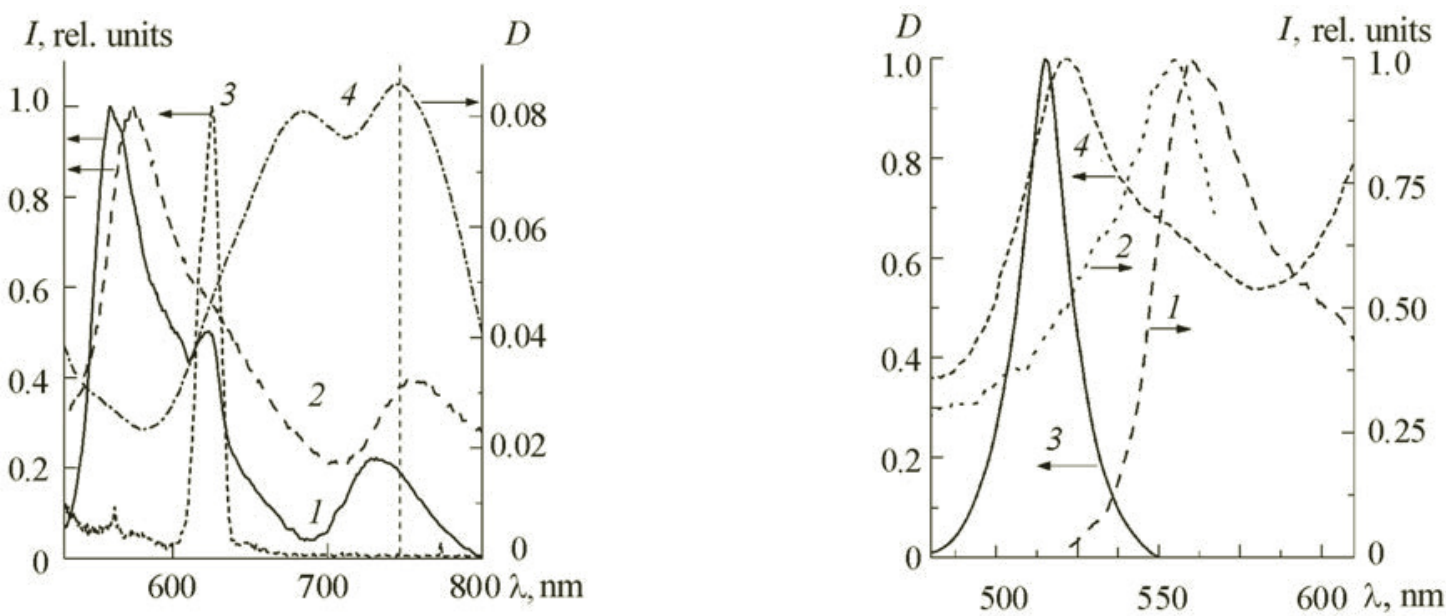

Fig. 6. Normalized fluorescence spectra $\left(\lambda_{\mathrm{ex}}=514.5 \mathrm{~nm}\right)$ of an aqueous EtOH solution of dye (1) and dye deposited on quartz substrate from aqueous EtOH (2); Raman spectrum of $\mathrm{H}_{2} \mathrm{O}$ (3); absorption spectrum of dye on quartz substrate (4).

Fig. 7. Normalized spectra of fluorescence with $\lambda_{\mathrm{ex}}=514.5 \mathrm{~nm}$ (1), fluorescence excitation with $\lambda_{\text {rec }}=590 \mathrm{~nm}$ (2), and absorption (3) of dye in aqueous EtOH; normalized dye absorption spectrum on quartz substrate (4).

shoulder of the short-wavelength $\mathrm{AB}$ corresponded to different absorbing centers. Furthermore, centers absorbing at $\sim 550$ $\mathrm{nm}$ and weakly fluorescing at the 560-nm maximum formed in solution and not on substrate. Fluorescence excitation spectra of dye deposited on quartz substrate could not be recorded because the fluorescence spectrometer was not sensitive enough.

The $\mathrm{AB}$ at $522 \mathrm{~nm}$ for sample on substrate could be attributed to $\mathrm{H}^{*}$-aggregates; the maximum at $684 \mathrm{~nm}$, to $\mathrm{H}$-dimers, because absorption spectra of dye in aqueous EtOH and on substrates were analogous. Assignment of the absorption maximum at $746 \mathrm{~nm}$ to dye monomers was dubious because in this instance, the Stokes shift of dye monomers on substrate would be on $160 \mathrm{~cm}^{-1}$ (Fig. 6, curves 2 and 4) whereas in solution, $614 \mathrm{~cm}^{-1}$. Hence, the nature of the AB maximum at $746 \mathrm{~nm}$ could be interpreted as follows. According to exciton theory, H-dimers possess two excited exciton states [67, 79]. The transition from the excitonic ground state into a lower one is forbidden when the dipole moments of molecules in dimers are parallel and directed to the same side; into an upper state, allowed. However, the transition into the lower state becomes allowed if the dipole moments become misaligned. Also, the intensity ratio of the corresponding ABs depends on the angle between the dimer molecule dipoles. Thus, dimers possess two ABs, one of which is shifted hypsochromically relative to the monomer spectrum; the other, bathochromically. The ratio of optical densities of the two ABs of dimers depends 


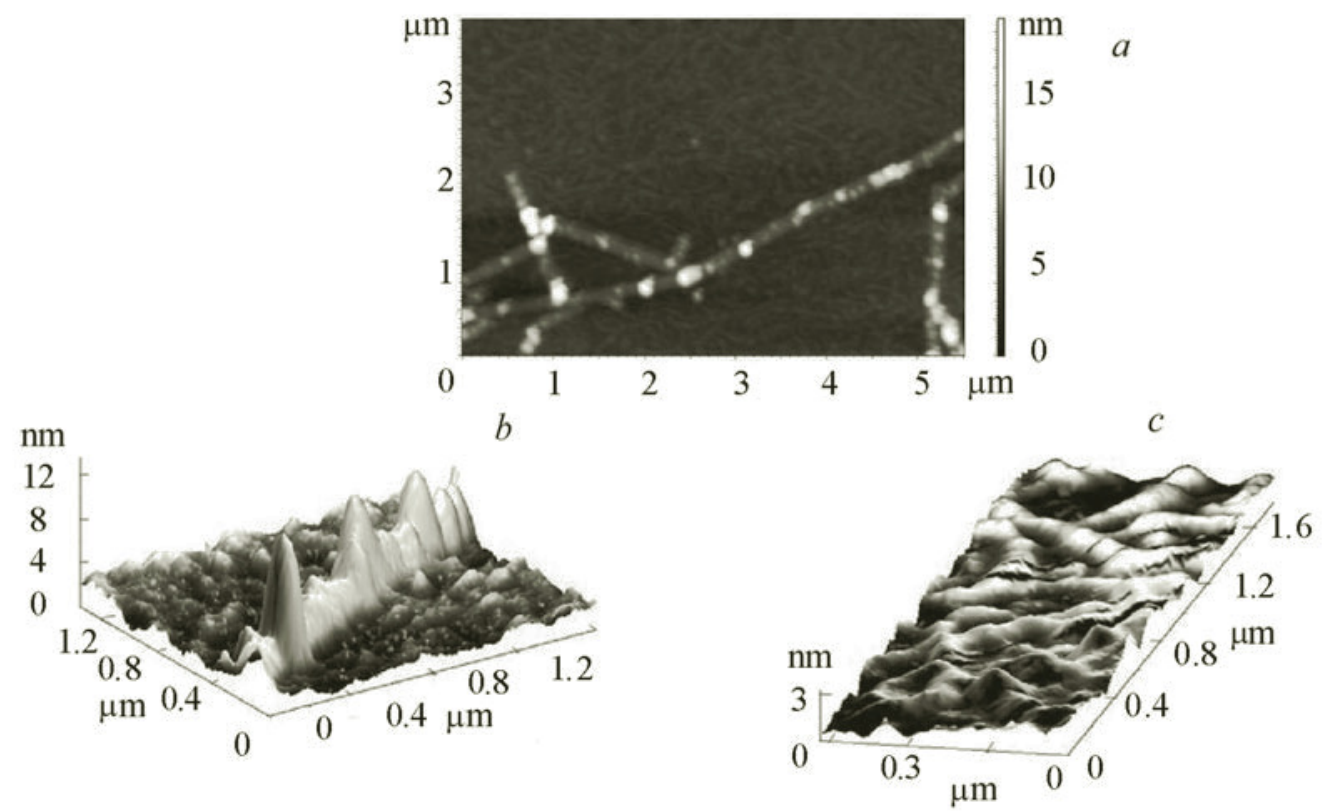

Fig. 8. Photomicrographs of indotricarbocyanine dye nanostructures obtained on an atomic-force microscope (a); three-dimensional image of rod-like nanostructure (b); three-dimensional image of irregularly shaped nanoparticles (c).

on the relative orientation of the molecules in them. It could be hypothesized that the mutual positioning of dye molecules in dimers changes as a result of interacting with the substrate. Therefore, their long-wavelength $\mathrm{AB}$ becomes stronger. Thus, the absorption maximum at $746 \mathrm{~nm}$ was due to superposition of $\mathrm{AB}$ of dimers corresponding to their transition into the lower excitonic state and $\mathrm{AB}$ of monomers. This hypothesis resolves the aforementioned discrepancies in the positions of dye $\mathrm{ABs}$ and fluorescence bands in solution and on substrate.

Thus, molecular aggregates absorbing at $\sim 550 \mathrm{~nm}$ with a fluorescence maximum at $560 \mathrm{~nm}$ formed in solution besides $\mathrm{H}$-dimers and $\mathrm{H}^{*}$-aggregates. The quantum yield of this emission was estimated by comparing its intensity with the spectral contribution of the water Raman band because absorption of centers responsible for the fluorescence could not be isolated. The fluorescence quantum yield could be considered low because the intensities of these bands were comparable. The hypsochromic shift of aggregate ABs relative to those of monomers and the low fluorescence quantum yield confirmed that this type of absorbing centers were H-aggregates [1]. In most instances, fluorescing $\mathrm{H}$-aggregates have large Stokes shifts $\left(5000-13,000 \mathrm{~cm}^{-1}\right)[70-72]$. In our instance, the Stokes shift of the H-aggregate fluorescence band of indotricarbocyanine dye was only $325 \mathrm{~cm}^{-1}$.

Spectral properties $[1,68,72,73]$ and a theoretical justification for the shape and position of their ABs [80-82] were the focus of studies with $\mathrm{H}^{*}$-aggregates. Also, the microscopic structure of $\mathrm{PD} \mathrm{H}^{*}$-aggregates has not been previously studied. Therefore, the morphologies of the molecular aggregates of indotricarbocyanine dye were investigated using an atomic-force microscope. It was found that two types of nanostructures appeared on silicon substrate (Fig. 8a), i.e., rod-like structures 5-15 nm high, $\sim 100 \mathrm{~nm}$ wide, and several micrometers long (Fig. 8b) and particles 1-3 nm high with lateral dimensions of $\sim 100 \mathrm{~nm}$ (Fig. 8c). The transverse dimensions of both types of nanostructures were significantly greater than their height. This may have been related to distortions caused by the microscope cantilever and deformation of nanostructures because of interaction with substrate.

Deposition of an aqueous EtOH dye solution on a slanted substrate so that the excess of liquid ran off followed by drying in a horizontal position produced anisotropically oriented rod-like nanostructures along the slant direction. The anisotropic orientation confirmed that the nanostructures formed in solution and not on the substrate during drying. Also, samples prepared by deposition on substrate of dye in organic solvents did not exhibit ABs at $\sim 520 \mathrm{~nm}$. Nanostructures were not observed.

The existence of two types of nanostructures of indotricarbocyanine dye agrees with results obtained using absorption and fluorescence spectroscopy. It should be considered that ABs of molecular aggregates are inhomogeneously broadened because of their disordered structures. The spectral width decreased with increasing number of dye molecules in them [83]. 
Furthermore, the fluorescence of H-aggregates increased if they became more disordered [27]. The rod-like nanostructures observed using an atomic-force microscope consisted of a large number of dye molecules and were highly disordered. Therefore, these nanostructures could be attributed to $\mathrm{H}^{*}$-aggregates with a characteristic narrow $\mathrm{AB}$ at $514 \mathrm{~nm}$ with FWHM of $21 \mathrm{~nm}$ in solution. The smaller nanoparticles were H-aggregates with ABs at $\sim 550 \mathrm{~nm}$ and weak fluorescence.

Conclusions. Studies of the spectral and luminescent properties of indotricarbocyanine dye in aqueous EtOH showed that dye dimers and $\mathrm{H}^{*}$-aggregates were present in solution. Long-wavelength fluorescence of the solution was due to monomers because dimers and $\mathrm{H}^{*}$-aggregates were non-fluorescent. Self-assembled dye $\mathrm{H}^{*}$-aggregates that formed in aqueous EtOH were deposited on quartz substrates and appeared on the surface as rod-like structures 5-15 $\mathrm{nm}$ high, $\sim 100 \mathrm{~nm}$ wide, and several micrometers long. Particles 1-3 nm high with lateral dimensions of $\sim 100 \mathrm{~nm}$ that were responsible for the asymmetry of the dye short-wavelength $\mathrm{AB}$ on substrate at $\sim 550 \mathrm{~nm}$ were $\mathrm{H}$-aggregates with weak fluorescence and a Stokes shift of $325 \mathrm{~cm}^{-1}$.

\section{REFERENCES}

1. A. H. Herz, Adv. Colloid Interface Sci., 8, No. 3, 237-298 (1977).

2. R. L. Parton and J. R. Lenhard, J. Org. Chem., 55, No. 3, $49-57$ (1990).

3. F. Wuerthner, R. Wortmann, and K. Meerholz, Chem. Phys. Chem., 3, No. 1, 17-31 (2002).

4. O. I. Tolmachev, N. V. Pilipchuk, O. D. Kachkovsky, Yu. L. Slominski, V. Ya. Gayvoronsky, E. V. Shepelyavyy, S. V. Yakunin, and M. S. Brodyn, Dyes Pigm., 74, No. 1, 195-201 (2007).

5. S. Barlow, J. L. Bredas, Yu. A. Getmanenko, R. L. Gieseking, J. M. Hales, H. Kim, S. R. Marder, J. W. Perry, C. Risko, and Y. Zhang, Mater. Horiz., 1, No. 6, 577-581 (2014).

6. Z. Sheng, D. Hu, M. Xue, M. He, P. Gong, and L. Cai, Nano-Micro Lett., 5, No. 3, 145-150 (2013).

7. K. Sano, T. Nakajima, T. Ali, D. W. Bartlett, A. M. Wu, I. Kim, C. H. Paik, P. L. Choyke, and H. Kobayashi, J. Biomed. Opt., 18, No. 10, 103041-1013046 (2013).

8. R. Watanabe, K. Sato, H. Hanaoka, T. Harada, T. Nakajima, I. Kim, C. H. Paik, A. M. Wu, P. L. Choyke, and H. Kobayashi, ACS Med. Chem. Lett., 5, No. 4, 411-415 (2014).

9. A. Yuan, J. Wu, X. Tang, L. Zhao, F. Xu, and Y. Hu, J. Pharm. Sci., 102, No. 1, 6-28 (2013),

10. X. Yi, F. Wang, W. Qin, X. Yang, and J. Yuan, Int. J. Nanomed., 9, 1347-1365 (2014).

11. A. A. Lugovski, M. P. Samtsov, K. N. Kaplevsky, D. Tarasau, E. S. Voropay, P. T. Petrov, and Yu. P. Istomin, J. Photochem. Photobiol., A, 316, 31-36 (2016).

12. R. B. Mujumdar, L. A. Ernst, S. R. Mujumdar, C. J. Lewis, and A. S. Waggoner, Bioconjugate Chem., 4, No. 2, 105-111 (1993).

13. A. Mishra, R. K. Behera, P. K. Behera, B. K. Mishra, and G. B. Behera, Chem. Rev., 100, No. 6, 1973-2012 (2004),

14. D. R. Dietze and R. A. Mathies, J. Phys. Chem. C, 119, No. 18, 9980-9987 (2015).

15. A. A. Ishchenko, Russ. Chem. Rev., 60, No. 8, 865-884 (1991).

16. V. I. Yuzhakov, Russ. Chem. Rev., 61, No. 6, 613-628 (1992).

17. L. Daehne and E. Biller, Adv. Mater., 10, No. 3, 241-245 (1998).

18. I. A. Struganova, H. Lim, and S. A. Morgan, J. Phys. Chem. B, 106, No. 42, 11047-11050 (2002).

19. A. K. Chibisov, H. Goerner, and T. D. Slavnova, Chem. Phys. Lett., 309, No. 1, 240-245 (2004).

20. C. Didraga, A. Pugzlys, P. R. Hania, H. von Berlepsch, K. Duppen, and J. Knoester, J. Phys. Chem. B, 108, 14976-14985 (2004).

21. A. Pugzlys, R. Augulis, P. H. M. van Loosdrecht, C. Didraga, V. A. Malyshev, and J. Knoester, J. Phys. Chem. B, 110, No. 41, 20268-20276 (2006).

22. H. von Berlepsch, S. Kirstein, R. Hania, A. Pugzlys, and C. Boettcher, J. Phys. Chem. B, 11, No. 7, 1701-1711 (2007).

23. B. I. Shapiro, E. A. Belonozhkina, and V. A. Kuz'min, Nanotechnol. Russ., 4, Nos. 1-2, 38-44 (2009).

24. F. C. Spano, J. Am. Chem. Soc., 131, No. 12, 4267-4278 (2009).

25. D. M. Eisele, J. Knoester, S. Kirstein, J. P. Rabe, and D. A. Vanden Bout, Nat. Nanotechnol., 4, No. 10, 658-663 (2009).

26. S. J. Khouri and V. Buss, J. Solution Chem., 39, No. 1, 121-130 (2010).

27. F. C. Spano, Acc. Chem. Res., 43, No. 3, 429-439 (2010).

28. F. Wuerthner, T. E. Kaiser, and C. R. Saha-Moeller, Angew. Chem., Int. Ed., 50, No. 15, 3376-3410 (2011).

29. D. M. Eisele, C. W. Cone, E. A. Bloemsma, S. M. Vlaming, C. G. F. van der Kwaak, R. J. Silbey, M. G. Bawendi, J. Knoester, J. P. Rabe, and D. A. Vanden Bout, Nat. Chem., 4, No. 8, 655-662 (2012). 
30. H. von Berlepsch and C. Boettcher, Langmuir, 29, No. 16, 4948-4958 (2013).

31. S. Chakraborty, P. Debnath, D. Dey, D. Bhattacharjee, and S. A. Hussain, J. Photochem. Photobiol., A, 93, 57-64 (2014).

32. K. A. Clark, E. L. Krueger, and D. A. Vanden Bout, J. Phys. Chem. C, 118, No. 42, 24325-24334 (2014).

33. N. Sato, T. Fujimura, T. Shimada, T. Tani, and S. Takagi, Tetrahedron Lett., 56, No. 22, 2902-2905 (2015).

34. J. Megow, M. I. S. Roehr, M. Schmidt am Busch, T. Renger, R. Mitric, S. Kirstein, J. P. Rabe, and V. May, Phys. Chem. Chem. Phys., 17, No. 10, 6741-6747 (2015).

35. J. R. Caram, S. Doria, D. M. Eisele, F. S. Freyria, T. S. Sinclair, P. Rebentrost, S. Lloyd, and M. G. Bawendi, Nano Lett., 16, No. 11, 6808-6815 (2016).

36. F. Milota, V. I. Prokhorenko, T. Mancal, H. von Berlepsch, O. Bixner, H. F. Kauffmann, and J. Hauer, J. Phys. Chem. A, 117, No. 29, 6007-6014 (2013).

37. H. von Berlepsch and C. Boettcher, J. Phys. Chem. B, 119, No. 35, 11900-11909 (2015).

38. C. Koenigstein, M. N. Spallart, and R. Bauer, Electrochim. Acta, 43, Nos. 16-17, 2435-2445 (1998).

39. M. Kawasaki and T. Sato, J. Phys. Chem. B, 105, No. 4, 796-803 (2001).

40. M. Kawasaki, D. Yoshidome, T. Sato, and M. Iwasaki, J. Electroanal. Chem., 543, No. 1, 1-11 (2003).

41. J. L. Lyon, D. M. Eisele, S. Kirstein, J. P. Rabe, D. A. Vanden Bout, and K. J. Stevenson, J. Phys. Chem. C, 112, No. 4, 1260-1268 (2008).

42. J. L. Lyon, D. M. Eisele, S. Kirstein, J. P. Rabe, D. A. Vanden Bout, and K. J. Stevenson, ECS Trans., 16, No. 28, 77-84 (2009).

43. C. W. Cone, S. Cho, J. L. Lyon, D. M. Eisele, J. P. Rabe, K. J. Stevenson, P. J. Rossky, and D. A. Vanden Bout, J. Phys. Chem. C, 115, No. 30, 14978-14987 (2011).

44. K. Takazawa, Y. Kitahama, and Y. Kimura, Chem. Commun., 20, 2272-2273 (2004).

45. K. Takazawa, Y. Kitahama, Y. Kimura, and G. Kido, Nano Lett., 5, No. 7, 1293-1296 (2005).

46. B. J. Walker, A. Dorn, V. Bulovic, and M. G. Bawendi, Nano Lett., 11, No. 7, 2655-2659 (2011).

47. Y. Qiao, F. Polzer, H. Kirmse, E. Steeg, S. Kirstein, and J. P. Rabe, J. Mater. Chem. C, 2, No. 43, 9141-9148 (2014).

48. Y. Qiao, F. Polzer, H. Kirmse, E. Steeg, S. Kuehn, S. Friede, S. Kirstein, and J. P. Rabe, ACS Nano, 9, No. 2, 1552-1560 (2015).

49. Y. Qiao, F. Polzer, H. Kirmse, S. Kirstein, and J. P. Rabe, Chem. Commun., 51, No. 60, 11980-11982 (2015).

50. A. Yoshida, N. Uchida, and K. Noritsugu, Langmuir, 25, No. 19, 11802-11807 (2009).

51. K. E. Achyuthan, A. M. Achyuthan, S. M. Brozik, S. M. Dirk, T. R. Lujan, J. M. Romero, and J. C. Harper, Anal. Sci., 28, No. 5, 433-438 (2012).

52. N. A. Toropov, P. S. Parfenov, and T. A. Vartanyan, J. Phys. Chem. C, 118, No. 31, 18010-18014 (2014).

53. R. D. Jansen-van Vuuren, P. C. Deakin, S. Olsen, and P. L. Burn, Dyes Pigm., 101, 1-8 (2014).

54. M. Kawasaki and S. Aoyama, Chem. Commun., 8, 988-989 (2004).

55. X. Ma, J. Hua, W. Wu, Y. Jin, F. Meng, W. Zhan, and H. Tian, Tetrahedron, 64, No. 2, 345-350 (2008).

56. A. N. Jordan, S. Das, N. Siraj, S.L. de Rooy, M. Li, B. El-Zahab, L. Chandler, G. A. Baker, and I. M. Warner, Nanoscale, 4, No. 16, 5031-5038 (2012).

57. P. K. D. Duleepa Pitigala, M. M. Henary, E. A. Owens, A. G. UnilPerera, and K. Tennakone, J. Photochem. Photobiol. A, 325, 39-44 (2016).

58. S. Kirstein and S. Daehne, Int. J. Photoenergy, 2006, 203631-203632 (2007).

59. D. M. Eisele, H. von Berlepsch, C. Boettcher, K. J. Stevenson, D. A. Vanden Bout, S. Kirstein, and J. P. Rabe, J. Am. Chem. Soc., 132, No. 7, 2104-2105 (2010).

60. L. I. Markova, V. L. Malinovskii, L. D. Patsenker, and R. Haener, Chem. Commun., 49, No. 46, 5298-5300 (2013).

61. R. L. Gieseking, S. Mukhopadhyay, C. Risko, S. R. Marder, and J. L. Bredas, Adv. Mater., 26, No. 1, 68-84 (2014).

62. J. Yuen-Zhou, D. H. Arias, D. M. Eisele, C. P. Steiner, J. J. Krich, M. G. Bawendi, K. A. Nelson, and A. Aspuru-Guzik, ACS Nano, 8, No. 6, 5527-5534 (2014).

63. E. Steeg, F. Polzer, H. Kirmse, Y. Qiao, J. P. Rabe, and S. Kirstein, J. Colloid Interface Sci., 472, 187-194 (2016).

64. E. E. Jelley, Nature, 138, No. 3502, 1009-1010 (1936).

65. E. E. Jelley, Nature, 139, No. 3519, 631-632 (1937).

66. G. Scheibe, Angew. Chem., 50, No. 11, 212-219 (1937).

67. M. Kasha, H. R. Rawls, and M. Ashraf El-Bayoumi, Pure Appl. Chem., 11, Nos. 3-4, 371-392 (1965).

68. H. Asanuma, K. Shirasuka, T. Takarada, H. Kashida, and M. Komiyama, J. Am. Chem. Soc., 125, No. 8, 2217-2223 (2003). 
69. J. Clark, J. F. Chang, F. C. Spano, R. H. Friend, and C. Silva, Appl. Phys. Lett., 94, No. 16, 1633061-1633063 (2009).

70. U. Roesch, S. Yao, R. Wortmann, and F. Wuerthner, Angew. Chem., Int. Ed., 45, No. 42, 7026-7030 (2006).

71. Q. Fang, F. Wang, H. Zhao, X. Liu, R. Tu, D. Wang, and Z. Zhang, J. Phys. Chem. B, 112, No. 10, 2837-2841 (2008).

72. N. Ryu, Y. Okazaki, E. Pouget, M. Takafuji, S. Nagaoka, H. Ihara, and R. Oda, Chem. Commun., 53, No. 63, 8870-8873 (2017).

73. A. V. Ruban, P. Horton, and A. J. Young, J. Photochem. Photobiol., B, 21, Nos. 2-3, 229-234 (1993).

74. N. V. Belko, M. P. Samtsov, G. A. Gusakov, E. S. Voropay, and L. S. Lyashenko, Zh. Prikl. Spektrosk., 83, Spec. Iss. 6-16, 458-459 (2016).

75. E. S. Emerson, M. A. Conlin, A. E. Rosenoff, K. S. Norland, H. Rodriguez, D. Chin, and G. R. Bird, J. Phys. Chem., 71, No. 8, 2396-2403 (1967).

76. C. A. Parker, Photoluminescence of Solutions with Applications to Photochemistry and Analytical Chemistry, Elsevier, New York (1968), 544 pp. [Russian translation, Mir, Moscow (1972), pp. 210-218].

77. V. Sundstrom and T. Gillbro, Chem. Phys., 61, 257-269 (1981).

78. G. E. Walfaren, J. Chem. Phys., 40, No. 11, 3249-3256 (1964).

79. V. V. Egorov and M. V. Alfimov, Usp. Fiz. Nauk, 117, No. 10, 1033-1081 (2007).

80. V. V. Egorov, J. Lumin., 131, No. 3, 543-547 (2011).

81. V. V. Egorov, AIP Adv., 14, No. 7, $0771111-0771119$ (2014).

82. V. V. Egorov, R. Soc. Open Sci., 4, No. 5, 160550-1-160550-2 (2017).

83. E. W. Knapp, Chem. Phys., 85, No. 1, 73-82 (1984). 